\title{
Overviews of Current Researches on Influential Factors of Effective Instruction in China
}

\author{
Qiujin Zhang \\ Division of Basic Science, Guangzhou Maritime Institute, Guangzhou, Guangdong Province, China \\ zhangqiujin@126.com
}

\begin{abstract}
In this paper, by using the literature analysis, current research literatures on influential factors of effective instruction in China are divided into two categories: one focus on the theoretical analysis, the other focus on empirical research, and the literatures are combed through and analysed. On this basis, this paper conducts a summary and reflection, and points out the lack of the research in the field and the direction of its development, with the aim to offer a reference for the evaluation standards and theoretical research of effective instruction, and to offer a basis and reference for teachers to implement effective instruction.

Index Terms - effective instruction, influential factors, teachers, students, literature analysis
\end{abstract}

\section{Introduction}

Effective instruction is the basic guarantee to promote high-quality instruction. Only when we clearly understand the affecting factors of effective instruction and its degree of influence can we put forward practical, effective strategies of instruction and effective standards of instruction. Currently, Chinese researchers haven't reached consensus about connotation of instruction effective, but some results have been commonly recognized by the scholars on the connotation of effective instruction. Such as making instruction to meet instructional rules, effective instruction is "effectual", "efficient", "cost-effective" instruction, and effective instruction should focus on the student's progress and its development [1]. Many researchers define the effective instruction from the perspective of students' progress and development and realize that effective instruction is the ability to promote student learning and development of instruction. So, this paper uses the concept of effective instruction to comb through and analyse the research status on influential factors of effective instruction in China, with the aim to offer a reference for the evaluation standards and theoretical research of effective instruction, and to offer a basis and reference for teachers to implement effective instruction.

\section{Current researches on influential factors of effective instruction in China}

\section{A. The concepts on influential factors of effective instruction}

Current domestic researchers about the understanding of the influencing factors of effective instruction is not uniform, most researchers is only from teachers teaching aspect to understand. In fact, instruction should include both the teacher's teaching and student's studying, it is not comprehensive enough to understand the influential factors of effective instruction only from teachers teaching aspect. Among numerous concepts on the influencing factors of effective instruction, the concept proposed by Yao Li-min is more complete. Yao Li-min proposes: the influential factors of effective instruction are the factors that affect teaching activities and contribute to achieve the desired teaching effectiveness. All factors in the teaching process, such as teaching environment, teachers, students, teaching content and so on, affect the effectiveness of teaching[2].

\section{B. Current researches on influential factors of effective instruction in China}

Effective instruction research in China can be traced back to the early 1980s, about 30 years of development history, the research is increasingly deepening, the number of the research literatures increase year by year, in these research literatures, the research literatures of the impact factors of effective instruction are not much. Fan Wei and Ye Bo, who study papers from 1990 - 2009 on effective instruction, divide the study content of effective instruction into the definition, influential factors, strategies and standards, but the study on effective instruction influencing factors accounted for only $13.6 \%$, indicating that current domestic related research in this area is not much[1].

Current research literatures on influential factors of effective instruction in China are mainly divided into two categories: one focus on the theoretical analysis, the other focus on empirical research.

In the theoretical analysis of influencing factors of effective instruction, most researches focus more on studying the factors of teachers than on the other affecting factors of effective instruction, putting the emphasis on teacher's quality or teacher's classroom behavior research. Some researchers from the teaching point of view, believe that teachers' impact on teaching is conducted by way of their teaching behavior, and they point out that the teaching ideas, knowledge, sense of responsibility, teaching efficacy, teaching ability, teaching resourcefulness and so on are the impact factors of effective teaching, and further describe these factors, and analyze the

The work is supported by Guangdong Province Education Science Plan Project (No. 2011TJK182) and Research Institute project of higher education and occupation education in Guangdong Province (No.GDGZ12Y071). 
relationship between these factors[3]. Some researchers point out that the implementation of effective instruction is decided not only by the ideas, but also by the teachers' career interests, working conditions, cognitive style, emotional state, personality characteristics, training factors of teachers and so on[4].

With further researches going on, researches have started to jump out from just putting the focus on the quality of teachers or teacher's classroom behavior, trying to examine affecting factors of effective instruction from many aspects, many angles. Through the systematic investigation and study of Western effective instruction research, some researchers give a comprehensive exposition of affecting factors on effective instruction of teachers. The researchers say: the understanding and grasp of the teachers' educational goals, especially curriculum goals and curriculum standards; teachers' good teaching quality, teaching behavior and teaching skills, and appropriate teaching strategies; teachers teaching practice and reflect on their own professional development, all of these are the factors influencing effective instruction[5]. Some researchers divide the affecting factors of effective instruction into positive factors and negative factors. Positive factors include teacher factors: teachers' education ideas, teachers' political and ideological and moral level, the teacher's intelligence and wisdom, scientific and cultural level of teachers, teachers' teaching ability, teacher's mental state; student factors: the general characteristics of the students, the students' starting ability, learning strategies and methods, student participation; teaching content factors: the value orientation of teaching content, how much teaching content; teaching environment factors: the physical and human environment of teaching. Negative factors include the theory without coming from practice, the lack of practical aspects; test-oriented teaching, not cultivating students morally; single teaching method, dull teaching atmosphere; out-dated teaching ideas [6].

In recent years, as for a specific course, some researchers give a comprehensive and integrated study on the affecting factors of effective teaching on the basis of characteristics of subject,. In these studies, some researchers, from the perspective of chemistry teaching, believe that the factors affecting effective instruction have three aspects, they are teachers' integration capabilities on course content, teachers' teaching philosophy, students' classroom participation consciousness[7]. For example, one researcher, as for the course "Teaching Chinese as a Foreign Language", based on the characteristics of subject, comprehensively analyses the affecting factors of effective instruction, and further analyses and explains the influence factors of effective instruction from the students, teachers, students' learning environment and so on, he points out: the influencing factors from teachers include teaching philosophy, ideological quality, expertise, teaching skills, cross-cultural communication skills, the ability to reflect; the influencing factors from students include learning motivation, language aptitude, intelligence, learning methods, learning styles, age level. In these factors, researcher's study focuses on teachers' behavior[8]. One researcher, from the external environment, students' learning psychology and teachers' teaching behavior, analyses the basic elements of implement effective instruction on school geography, and conducts that the external environment is the background element, students' learning psychology is the basis element, teachers' teaching behavior is the core element for implementation of effective instruction on geography[9].

Now more and more researchers begin to focus on empirical research of effective teaching, especially more and more attention is paid to empirical researches of university effective teaching.

Through the questionnaire survey of college students, some researchers empirically research the impact factors on effective teaching of college teachers, and point out that the academic standards of teachers, teaching and students' actual degree of integration in teaching process, training students' thinking abilities and teaching students study methods and methodology impose a great influence on the teaching effectiveness[10]. Some researchers from teachers' teaching perspective, empirically study the impact of teachers, students, institutions on effective teaching in classroom. Investigation shows that effective teaching in classroom depends on teachers, students and institutions; the influence of teachers is realized by teaching philosophy, sense of responsibility in teaching, teaching input, teaching knowledge, teaching efficacy, and their learning, practice, reflection, and research on teaching; the influence of students is achieved by their cooperation, support and commitment; the influence of institutions is dependent on their attention, encouragement, and support to effective teaching [11].

As the quality of student achievement reflects the quality of instruction, using multiple regression analysis, from the students' point of view, a researcher empirically studies the factors affecting the effectiveness of instruction. Investigation shows: college students' behavior has a greater impact on student achievement; learning environment also has some impact on student achievement. This proves that the students' learning behavior is an important factor affecting effective instruction [12].

Through the questionnaire survey to student representatives and the senior experts who have long been engaged in teaching, teaching management and college management, some researchers from the perspective of a more comprehensive, empirically analyse factors affecting instruction quality in college. Investigation shows: sorted in order of importance, the main influencing factors of instruction quality are: teachers, teaching management, students and social factors. Among them, the critical dominant factors are teaching design, teacher style, teaching management system [13].

\section{Summary and Reflection}

Current research literatures on influential factors of effective instruction in China are divided into two categories: one focus on the theoretical analysis, the other focus on empirical research, and the literatures are combed through and 
analysed. Most of the literatures on the theoretical analysis study teachers' factors affecting effective instruction; the literatures on the empirical research mainly study the influential factors of effective instruction in college.

As for current Chinese research on influential factors of effective instruction, although the research has transferred from a single perspective of teachers to a comprehensive multi-angle, there are some limitations and shortcomings:

The distribution of the study contents is not very balanced, most of the studies focus on teachers factors, few studies are related to students and so on; most of empirical studies just use questionnaire method to analyse the survey data, and then fail to provide us with information about the actual effectiveness of instruction ; empirical studies, has considered influential factors of effective instruction from more comprehensive multi-angle, but what factors on the impact of effective instruction, how they come into force and how much they can affect it are less discussed.

There are many factors affecting effective instruction, but what is important, what are the key factors, and how these factors affect instruction are the problems to be further studied.

\section{References}

[1] Fan Wei, Ye Bo. Summary and Comment of Researches on Effective Instruction since 1990, Journal of Chongqing University (Social Science Edition), vol.16(4), pp.133-137, 2010.
[2] Yao Li-min. Research on Effective Teaching: Shanghai: East China Normal University, pp. 23, 2004.

[3] Yao Li-min. The exploration and analysis of the teachers' factors affecting effective teaching, Journal of Higher Education Research, vol. 27(1), pp. 4-6, 2004

[4] Yan Yun-tang. Analysis of the factors that restrict teachers the effectiveness of teaching, Journal of Teaching and Management, (11), pp. $8-9,2004$.

[5] Chen Xiao-duan, Stephen, Keith. Research on effective teaching modern Western countries: systematical review and some inspirations, Comparative Education Review, (8), pp. 56- 71, 2005.

[6] Sun Ya-ling. Research on the standards of effectiveness on classroom teaching, Beijing: Education Science Press, 2008, pp.94-130.

[7] Liu De-gong. Study on the structure and influencing factors of effective teaching of chemistry: Nanjing: Nanjing Normal University, 2010.

[8] Huang Xiao-ying. The Study of effective teaching in teaching Chinese as a foreign language: Changchun: Northeast Normal University, 2011.

[9] Li Ya-jie. The factors analysis and strategy research of effective teaching on middle school geography: Nanjing: Nanjing Normal University, 2008.

[10] Wang Shu-fang, Lei Shu-he and Wang Hong-xin. Research on effective teaching in the University, Research in Higher Education of Engineering, (4), pp.90 - 92, 2006

[11] Cao Xia, Yao Li-min and Huang Shu-zhen. On Effects of Teacher, Student and Institution on Effective Classroom Teaching in University \& College, University Education Science, (1), pp.25-31,2012.

[12] Qiujin Zhang. The Application of Multiple Linear Regress Equation on Analysing the Effect Factors of Student Scores: IEEE.ICMT2011: The International workshop on physics and mathematics. NY, USA: Curran Associates,Inc, 2011, pp.6087-6089.

[13] Zhang Bo, Yang Lei, Ma Li-yan, Li Wen-qin, Wu Yan-yan and Zhang Qian-zheng. Empirical analysis on the influencing factors of teaching quality, Journal of Agricultural University of Hebei (Agricultural \& Forestry Education), vol.11( 1), pp. 50-54, 2009. 